\title{
Histological correlation of pipelle endometrial sampling with dilatation and curettage in abnormal uterine bleeding
}

\author{
Lavanya Rachamallu ${ }^{1 *}$, Bhavani $V^{2}$, Prasanna Byna ${ }^{1}$
}

\author{
${ }^{1}$ Department of Obstetrics \& Gynaecology, Narayana Medical College \& Hospitals, Nellore-524003, A.P., India \\ ${ }^{2}$ Department of Obstetrics \& Gynaecology, Sri Venkateswara Medical College, Tirupati, A.P., India
}

Received: 08 July 2015

Revised: 03 August 2015

Accepted: 13 August 2015

\section{*Correspondence:}

Dr. Lavanya Rachamallu,

E-mail: research.nmch@rediffmail.com

Copyright: (C) the author(s), publisher and licensee Medip Academy. This is an open-access article distributed under the terms of the Creative Commons Attribution Non-Commercial License, which permits unrestricted non-commercial use, distribution, and reproduction in any medium, provided the original work is properly cited.

\begin{abstract}
Background: The current study was aimed to compare histopathological findings of endometrial aspiration biopsy by pipelle with endometrial biopsy obtained by dilatation and curettage.

Methods: 82 women attending to gynaec OPD with complaint of AUB were selected as cases. First pipelle aspiration biopsy was done was before cervical dilatation and followed by D\&C. Histopathology report of pipelle sample was compared with D\&C sample.
\end{abstract}

Results: There In the present study, menorrhagia was the most common bleeding pattern $43(52.4 \%)$. In pipelle aspiration biopsy group, endometrial hyperplasia was reported in $42.6 \%$ of patients, secretory endometrium in $14.6 \%$ of patients, proliferative endometrium in $32.9 \%$ of patients, atrophic endometrium in $6 \%$ of patients and malignancy in $3.6 \%$ of patients. In D\&C group, $39(47.5 \%)$ of patients had endometrial hyperplasia followed by proliferative endometrium in $24(29.3 \%)$ of patients, secretory endometrium in $14.6 \%$ of patients, atrophic endometrium in $4.8 \%$ of patients and malignancy in $3.6 \%$ of patients. In D\&C group, 39 patients had hyperplasia. Among them, 24 patients (61.5\%) had simple hyperplasia, 11 patients (28.2\%) had complex hyperplasia, 4 patients (10.2\%) had atypical hyperplasia. In pipelle aspiration biopsy group, 35 patients had endometrial hyperplasia. Among them, 20 patients (57.1\%) had simple hyperplasia, 11 patients (31.4\%) had complex hyperplasia, 4 patients (11.4\%) had atypical hyperplasia. Out of 82 cases, D \& C diagnosed 46 cases as abnormal endometrium and pipelle aspiration diagnosed only 43 as abnormal endometrium. Regarding abnormal endometrium, there was a correlation in pipelle aspiration group and D\&C group. Both show substantial agreement between the studies. Pipelle aspiration also has high sensitivity and negative predictive value of $93.47 \%$ and $92.3 \%$ respectively in diagnosing abnormal endometrium. In 46 patients who had endometrial pathology, pipelle aspiration biopsy diagnosed correctly in 42 patients. 4 cases of hyperplasia were wrongly diagnosed as proliferative endometrium in 3 cases, and in 1case as atrophic endometrium. Pipelle sampling has diagnosed all cases of malignancy, atrophy and secretory endometrium correctly. Pipelle aspiration also has high sensitivity and negative predictive value of $89.7 \%$ and $91.4 \%$ respectively in diagnosing hyperplastic endometrium.

Conclusions: Hence pipelle aspiration biopsy is an alternative to traditional D\& $\mathrm{C}$ in diagnosing endometrial pathology which is safer and quick.

Keywords: Pipelle endometrial sampling, Hyperplasia, Dilatation and curettage, Abnormal uterine bleeding 


\section{INTRODUCTION}

Abnormal uterine bleeding is one of the most frequent menstrual problems constitute about $15-20 \%$ of patients presenting to a gynaec OPD. It includes heavy and or prolonged periods and any form of irregular bleeding per vaginum. ${ }^{1}$ Abnormal uterine bleeding is a symptom and not a disease. ${ }^{2}$ These menstrual aberrations occur mostly at the extremes of reproductive life. This proportion rises to $69 \%$ when the perimenopausal and postmenopausal age groups are considered. ${ }^{3}$

AUB may be due to abnormalities of reproductive tract which may be benign (polyp, fibroids, endometriosis, etc.) or malignant or it may be due to infections, pregnancy related complications, iatrogenic factors and systemic diseases. However, in majority of cases there are no underlying structural abnormalities and this is called dysfunctional uterine bleeding.

AUB warrants a thorough evaluation in peri and postmenopausal women in order to rule out, serious pathology like endometrial cancer and its precursors such as complex hyperplasia. Risk of endometrial cancer in postmenopausal women with bleeding is $15 \%$. $^{4}$ So, early diagnosis, improves the prognosis.

Abnormal uterine bleeding can be evaluated by ultrasound, saline infusion sonography, endometrial biopsy, hysteroscopy, etc. Histological examination of endometrial tissue remains the standard diagnostic procedure for abnormal uterine bleeding.

For years, Dilatation and Curettage (D\&C) was used for endometrial tissue sampling. But because of the associated surgical risks, expense, postoperative pain, and need for operative anesthesia, other suitable substitutes were evaluated. ${ }^{5}$ To minimize these, a variety of thin, flexible plastic samplers have been evaluated, with comparable histologic findings from tissues obtained by D\&C, hysterectomy, or stiff metal curette. ${ }^{6}$ Many different methods have been developed to minimize the need for curettage like vibra aspirator, pipelle aspiration but their diagnostic accuracy is debated.

Hence a procedure which is minimally invasive with better diagnostic accuracy, no risk of complications, well accepted by the patient, which is easy to learn and perform is needed.

\section{METHODS}

This is a prospective study conducted at the Government Maternity Hospital, Tirupati from August 2011 to October 2012.

In the present study, 82 women attending to gynaec OPD with complaint of AUB were selected as cases. Patients were selected on the basis of inclusion and exclusion criteria. Detailed history evaluated from them regarding duration of complaint, menstrual history, drug intake and other associated medical illness. Routine blood investigations and urine analysis were done. After getting written consent from selected patients they were planned for endometrial biopsy by pipelle and D\&C as a day care procedure. Both procedures were performed in OT at same time. First pipelle aspiration biopsy was done before cervical dilatation and followed by D\&C. Both the samples were sent for histopathology separately. Histopathology report of pipelle sample was compared with D\&C sample.

\section{Inclusion criteria}

1. All women with abnormal uterine bleeding.

2. No obvious cervical and genital lesions.

3. Not on hormonal therapy.

4. No evidence of any haematological disorder.

5. No contraindications for dilatation \& curettage study.

\section{Exclusion criteria}

1. Unwilling patients.

2. Suspected pelvic infection.

3. Profusely bleeding patients requiring therapeutic curettage.

4. Women on oral contraceptives.

5. Premalignant and malignant lesions of cervix.

6. Cervical stenosis.

7. Severe medical conditions precluding study - like uncontrolled HTN, DM.

8. Pregnancy and related causes of bleeding PV.

\section{RESULTS}

82 women with AUB were included as study group. For all women pipelle sampling followed by D\&C done and material sent for histopathological examination.

Table 1: AUB - age distribution.

\begin{tabular}{|lll|}
\hline Age (years) & $\mathrm{n} / \mathrm{t}$ & $\%$ \\
\hline$<35$ & 13 & 15.8 \\
\hline $36-40$ & 24 & 29.2 \\
\hline $41-45$ & 27 & 32.9 \\
\hline $46-50$ & 13 & 15.8 \\
\hline $51-55$ & 5 & 6 \\
\hline
\end{tabular}

Most of patients in this study were between 41-45 years of age $(32.9 \%)$.

Table 2: AUB - parity.

\begin{tabular}{|lll|}
\hline Parity & $\mathrm{n} / \mathrm{t}$ & $\%$ \\
\hline Nulliparous & $2 / 82$ & 2.4 \\
\hline Para 1 & $8 / 82$ & 9.7 \\
\hline Para 2 & $38 / 82$ & 46.3 \\
\hline Para 3 & $22 / 82$ & 26.8 \\
\hline Para 4 and above & $12 / 82$ & 14.6 \\
\hline
\end{tabular}


Highest incidence of abnormal uterine bleeding in our study was among para $2(46.3 \%)$ followed by para 3 $(26.8 \%)$.

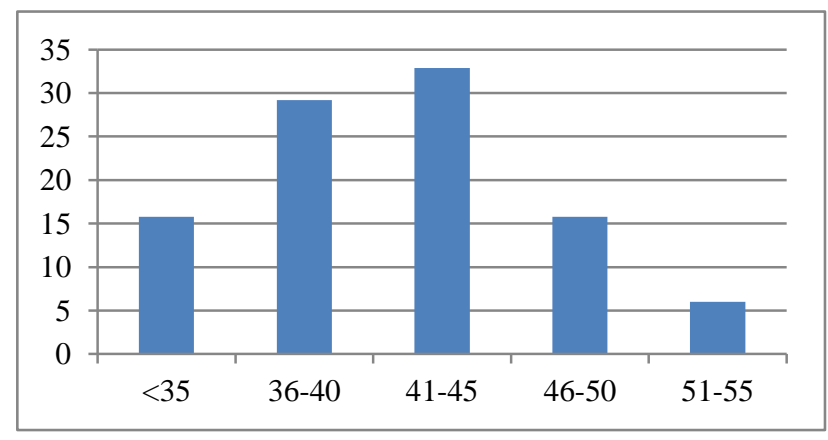

Figure 1: Age distribution.

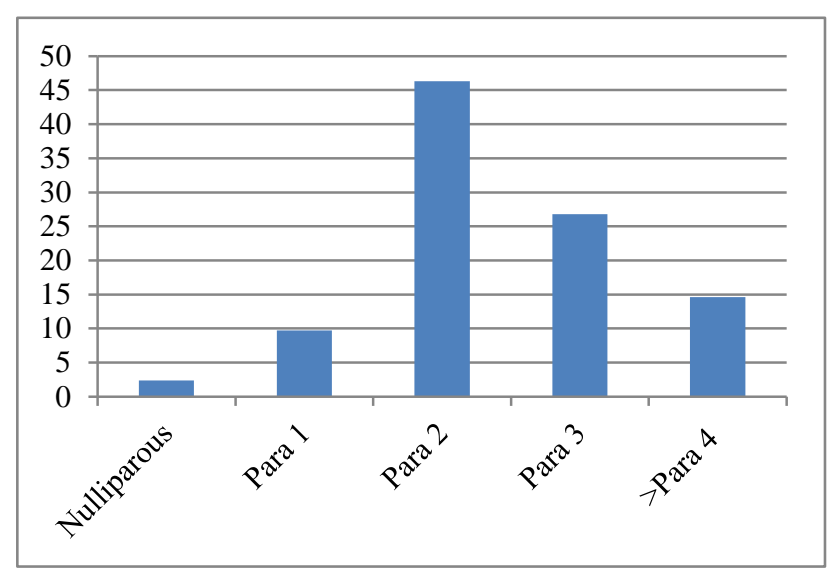

Figure 2: Parity.

Table 3: AUB - bleeding pattern.

\begin{tabular}{|lll|}
\hline Type of bleeding abnormality & $\mathrm{n} / \mathrm{t}$ & $\%$ \\
\hline Menorrhagia & $43 / 82$ & 52.4 \\
\hline Metrorrhagia & $8 / 82$ & 9.7 \\
\hline Polymenorrhoea & $10 / 82$ & 12.1 \\
\hline Polymenorrhagia & $6 / 82$ & 7.3 \\
\hline Metropathia haemorrhagica & $10 / 82$ & 12.1 \\
\hline Menometrorrhagia & $5 / 82$ & 6.1 \\
\hline
\end{tabular}

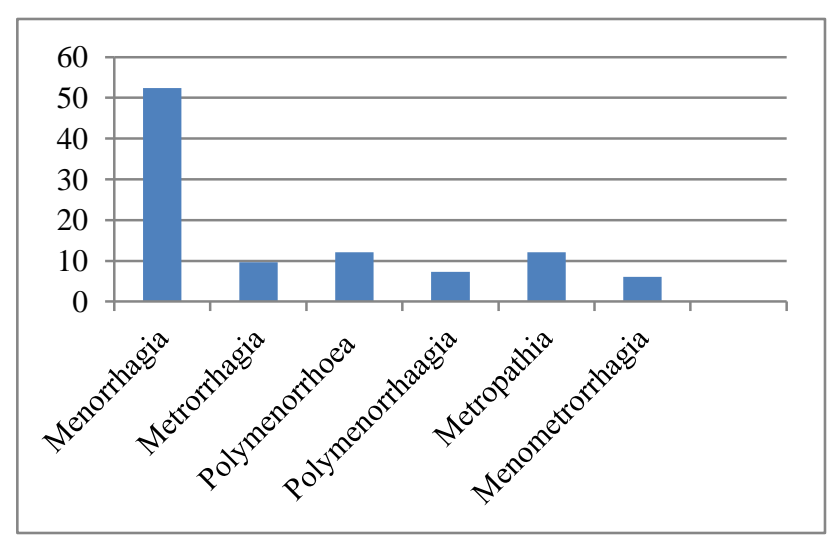

Figure 3: Bleeding pattern.
In the present study, menorrhagia was the most common bleeding pattern $43(52.4 \%)$ followed by metropathia haemorrhagica $10(12.1 \%)$ and polymenorrhoea 10 (12.1\%).

Table 4: Histopathology - Pipelle aspiration biopsy.

\begin{tabular}{|lll|}
\hline Histopathology & $\mathrm{n} / \mathrm{t}$ & $\%$ \\
\hline Secretory endometrium & $12 / 82$ & 14.6 \\
\hline Proliferative endometrium & $27 / 82$ & 32.9 \\
\hline Atrophy & $5 / 82$ & 6 \\
\hline Endometrial hyperplasia & $35 / 82$ & 42.6 \\
\hline Malignancy & $3 / 82$ & 3.6 \\
\hline
\end{tabular}

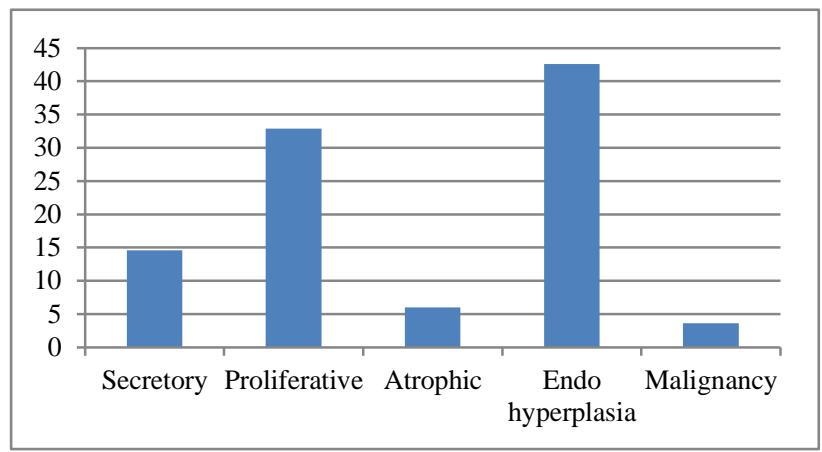

Figure 4: Histopathology - Pipelle aspiration biopsy.

In pipelle aspiration biopsy group, endometrial hyperplasia was reported in $42.6 \%$ of patients, secretory endometrium in $14.6 \%$ of patients, proliferative endometrium in $32.9 \%$ of patients, atrophic endometrium in $6 \%$ of patients and malignancy in $3.6 \%$ of patients.

Table 5: Histopathology - D\&C.

\begin{tabular}{|lll|}
\hline Histopathology & $\mathrm{n} / \mathrm{t}$ & $\%$ \\
\hline Secretory endometrium & $12 / 82$ & 14.6 \\
\hline Proliferative endometrium & $24 / 82$ & 29.3 \\
\hline Atrophy & $4 / 82$ & 4.8 \\
\hline Endometrial hyperplasia & $39 / 82$ & 47.5 \\
\hline Malignancy & $3 / 82$ & 3.6 \\
\hline
\end{tabular}

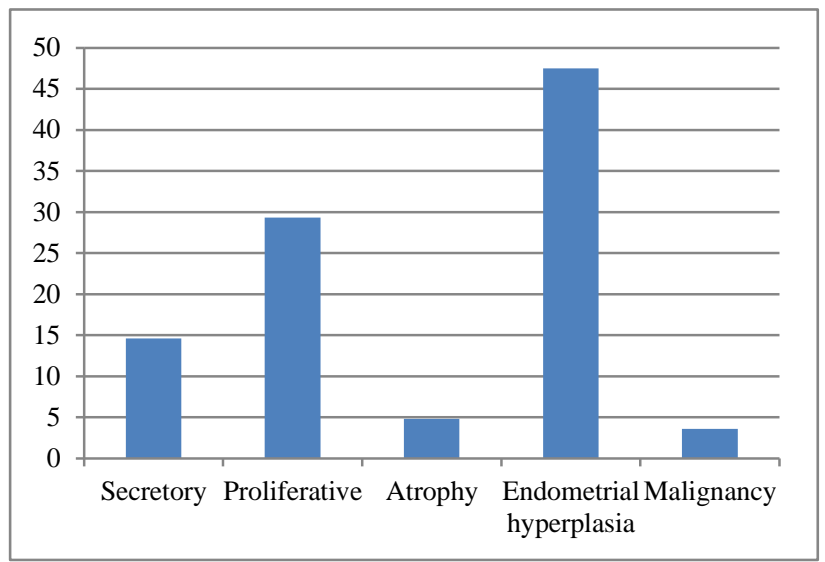

Figure 5: Histopathology - D\&C. 
In D\&C group, 39 (47.5\%) of patients had endometrial hyperplasia followed by proliferative endometrium in 24 (29.3\%) of patients, secretory endometrium in $14.6 \%$ of patients, atrophic endometrium in $4.8 \%$ of patients and malignancy in $3.6 \%$ of patients.

Table 6: Endometrial hyperplasia - D\&C.

\begin{tabular}{|lll|}
\hline Endometrial hyperplasia & $\mathrm{n} / \mathrm{t}$ & $\%$ \\
\hline Simple hyperplasia & $24 / 39$ & 61.5 \\
\hline Complex hyperplasia & $11 / 39$ & 28.2 \\
\hline Atypical hyperplasia & $4 / 39$ & 10.2 \\
\hline
\end{tabular}

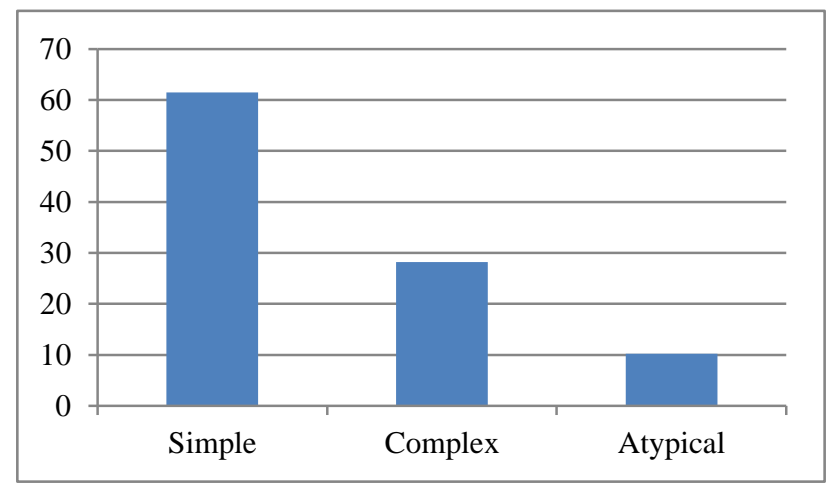

Figure 6: Endometrial hyperplasia - D\&C.

In D\&C group, 39 patients had hyperplasia. Among them, 24 patients $(61.5 \%)$ had simple hyperplasia, 11 patients $(28.2 \%)$ had complex hyperplasia, 4 patients $(10.2 \%)$ had atypical hyperplasia.

Table 7: Endometrial hyperplasia - Pipelle aspiration biopsy.

\begin{tabular}{|lll|}
\hline Endometrial hyperplasia & $\mathrm{n} / \mathrm{t}$ & $\%$ \\
\hline Simple hyperplasia & $20 / 35$ & 57.1 \\
\hline Complex hyperplasia & $11 / 35$ & 31.4 \\
\hline Atypical hyperplasia & $4 / 35$ & 11.4 \\
\hline
\end{tabular}

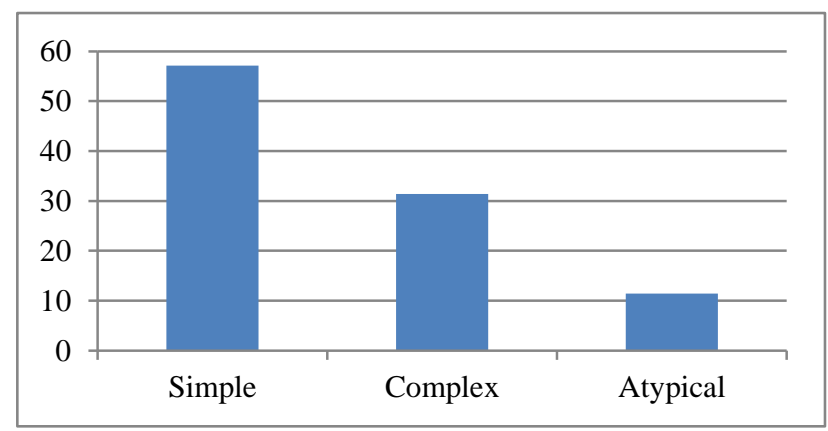

Figure 7: Endometrial hyperplasia - PAS.

In pipelle aspiration biopsy group, 35 patients had endometrial hyperplasia. Among them, 20 patients $(57.1 \%)$ had simple hyperplasia, 11 patients $(31.4 \%)$ had complex hyperplasia, 4 patients $(11.4 \%)$ had atypical hyperplasia.
Table 8: HPE - Pipelle aspiration biopsy group vs. D\&C group.

\begin{tabular}{|llll|}
\hline $\begin{array}{l}\text { Pipelle } \\
\text { aspiration } \\
\text { biopsy }\end{array}$ & Abnormal & Normal & Total \\
\hline Abnormal & $43(\mathrm{a})$ & $0(\mathrm{~b})$ & 43 \\
\hline Normal & $3(\mathrm{c})$ & $36(\mathrm{~d})$ & 39 \\
\hline Total & 46 & 36 & 82 \\
\hline
\end{tabular}

Out of 82 cases, D \& C diagnosed 46 cases as abnormal endometrium and pipelle aspiration diagnosed only 43 as abnormal endometrium.

$$
\begin{array}{ll}
\text { Sensitivity } & =\mathrm{a} / \mathrm{a}+\mathrm{c} 100=43 / 43+3100=93.47 \% \\
\text { Specificity } & =\mathrm{d} / \mathrm{b}+\mathrm{d} 100=36 / 0+36100=100 \% \\
\text { PPV } & =\mathrm{a} / \mathrm{a}+\mathrm{b} 100=43 / 43+0100=100 \% \\
\text { NPV } & =\mathrm{d} / \mathrm{c}+\mathrm{d} 100=36 / 3+36100=92.3 \%
\end{array}
$$

Accuracy of concordance $=(\mathrm{a}+\mathrm{d}) / \mathrm{n} 100=43+36 / 82100$ $=96.3 \%$

Kappa statistics $=0.92$ very good agreement.

Regarding abnormal endometrium, there was a correlation in pipelle aspiration group and D\&C group. Both show substantial agreement between the studies. pipelle aspiration also has high sensitivity and negative predictive value of $93.47 \%$ and $92.3 \%$ respectively in diagnosing abnormal endometrium.

Table 9: HPE - Pipelle aspiration biopsy vs. D\&C group.

\begin{tabular}{|lll|}
$\begin{array}{l}\text { Types of endometrial } \\
\text { pathology }\end{array}$ & $\begin{array}{l}\text { Aspiration } \\
\text { biopsy } \\
\text { findings }\end{array}$ & $\begin{array}{l}\text { D\&C } \\
\text { reports }\end{array}$ \\
\hline Secretory endometrium & 12 & 12 \\
\hline Proliferative endometrium & 27 & 24 \\
\hline Atrophy & 5 & 4 \\
\hline Hyperplasia & 35 & 39 \\
\hline Malignancy & 3 & 3 \\
\hline Total & 82 & 82 \\
\hline
\end{tabular}

In 46 patients who had endometrial pathology, pipelle aspiration biopsy diagnosed correctly in 42 patients. 4 cases of hyperplasia were wrongly diagnosed as proliferative endometrium in 3 cases, and in 1case as atrophic endometrium. Pipelle sampling has diagnosed all cases of malignancy, atrophy and secretory endometrium correctly.

In D\&C group, endometrial pathology was diagnosed correctly in all cases. 


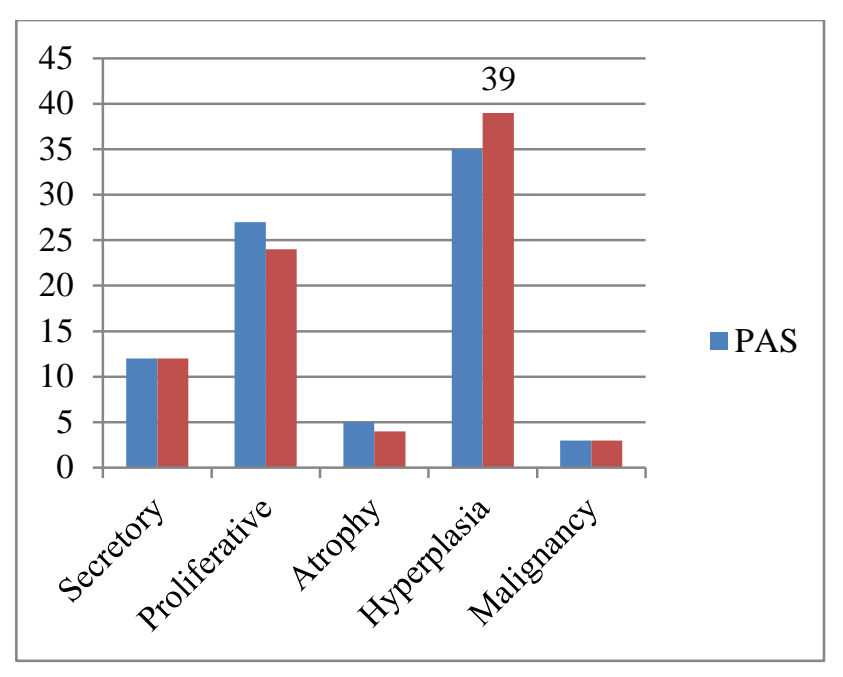

Figure 9: HPE - Pipelle aspiration biopsy vs. D\&C group.

Table 10: Endometrial hyperplasia: Pipelle aspiration vs. D\&C.

\begin{tabular}{|lll|}
\hline Procedure & $\mathrm{n} / \mathrm{t}$ & $\%$ \\
\hline D\&C group & $39 / 39$ & 100 \\
\hline Pipelle aspiration group & $35 / 39$ & 89.74 \\
\hline
\end{tabular}

Out of 39 cases of hyperplasia pipelle sampling correctly diagnosed 35 cases.

$$
\begin{array}{ll}
\text { Sensitivity } & =\mathrm{a} / \mathrm{a}+\mathrm{c} 100=35 / 35+4100=89.7 \% \\
\text { Specificity } & =\mathrm{d} / \mathrm{b}+\mathrm{d} 100=43 / 0+43100=100 \% \\
\text { PPV } & =\mathrm{a} / \mathrm{a}+\mathrm{b} 100=35 / 35+0100=100 \% \\
\text { NPV } & =\mathrm{d} / \mathrm{c}+\mathrm{d} 100=43 / 4+43100=91.4 \%
\end{array}
$$

Accuracy of concordance $=(\mathrm{a}+\mathrm{d}) / \mathrm{n} 100=35+43 / 82100$ $=95.1 \%$

Kappa statistics $=0.9$ very good agreement.

Pipelle aspiration also has high sensitivity and negative predictive value of $89.7 \%$ and $91.4 \%$ respectively in diagnosing hyperplastic endometrium.

Table 11: Malignancy - Pipelle aspiration vs. D\&C.

\begin{tabular}{|lll|}
\hline Procedure & $\mathrm{n} / \mathrm{t}$ & $\%$ \\
\hline Pipelle aspiration group & $3 / 3$ & 100 \\
\hline D\&C group & $3 / 3$ & 100 \\
\hline
\end{tabular}

Both pipelle and D\&C diagnosed all cases of malignancy.

$$
\begin{array}{ll}
\text { Sensitivity } & =\mathrm{a} / \mathrm{a}+\mathrm{c} 100=3 / 3+0100=100 \% \\
\text { Specificity } & =\mathrm{d} / \mathrm{b}+\mathrm{d} 100=79 / 0+79100=100 \%
\end{array}
$$

PPV

NPV

$$
\begin{aligned}
& =a / a+b 100=3 / 3+0100=100 \% \\
& =d / c+d 100=79 / 0+79100=100 \%
\end{aligned}
$$

Accuracy of concordance $=(a+d) / n 100=3+79 / 82100=$ $100 \%$

Kappa statistics $=1$ very good agreement.

Pipelle aspiration also has high sensitivity and negative predictive value of $100 \%$ and $100 \%$ respectively in diagnosing malignancy of endometrium.

\section{DISCUSSION}

Histological diagnosis of endometrial tissue is important especially in perimenopausal women with AUB to confirm the benign nature of the problem and to rule out endometrial carcinoma.so that medical treatment or conservative surgery can be offered and unnecessary radical surgeries can be avoided.

In the present study group of 82 patients, endometrial aspiration biopsy with pipelle and dilatation and curettage was done. In the present study, $49 \%$ of the patients were 41-50 years which is close to study done by Fouzia Yasmin et al. ${ }^{7}$ and S. Vaidya et al. ${ }^{8}$

In the present study, $88 \%$ of patients were multipara which is not correlating with any of the studies.

In the present study, $52 \%$ of patients presented with menorrhagia and metrorrhagia in $9.7 \%$ of patients which is close to study done by Bhavani et al. ${ }^{9}$ i.e.; $54 \%$ and $6.5 \%$ respectively. polymenorrhoea and polymenorrhagia together constituted $19.4 \%$ which is close to the study done by Avantika Gupta et al. ${ }^{10}(20 \%)$.

In the present study group of 82 patients, secretory and proliferative type of endometrium is seen in $47 \%$ of patients which is close to study done by Gerald Dafe Forae et al. ${ }^{11}(42.4 \%)$, endometrial hyperplasia was seen in $42.6 \%$ of patients which is close to the study done by Supriya Sandeepa et al. ${ }^{12}(38 \%)$ and endometrial carcinoma was noted in $3 \%$ which is correlating with the study by Avantika Gupta et al. ${ }^{10}(3 \%)$.

In pipelle aspiration biopsy group, out of 4 cases of simple endometrial hyperplasia were diagnosed as proliferative endometrium in 3 and atrophic endometrium in 1 case. The pipelle aspiration biopsy has sensitivity of $89.7 \%$, specificity $100 \%$, PPV $100 \%$, NPV $91.4 \%$ which is correlating to the study done by Fouzia Yasmin et al. ${ }^{7}$ which is $100 \%, 84 \%$ and $100 \%$ respectively and the accuracy rate was $95 \%$ in both the studies.

In the present study, pipelle aspiration biopsy was $100 \%$ sensitivity, specificity, positive predictive and negative predictive value in diagnosing endometrial carcinoma which is correlating with study done by Nadia Khurshid et al. ${ }^{13}(100 \%)$. 


\section{CONCLUSIONS}

For the purpose of maintaining synchronicity in the timing of sample, the pipelle method was performed at the time of D\&C in our study. But otherwise pipelle is an outpatient procedure that can be performed without anaesthesia, analgesia, premedication and cervical dilatation that can be done at the same time of pelvic examination. Hence pipelle aspiration biopsy is an alternative to traditional $\mathrm{D} \& \mathrm{C}$ in diagnosing endometrial pathology which is safer and quick.

Funding: No funding sources

Conflict of interest: None declared

Ethical approval: The study was approved by the institutional ethics committee

\section{REFERENCES}

1. Chamberlain GVP. Abnormal uterine bleeding. In: Chamberlain GVP, eds. Gynecology by Ten Teachers. 16th ed. London: Arnold; 1995: 173-175.

2. Kumar. Clinical types of abnormal uterine bleeding. In: Kumar, eds. Jeffcoate's Principle of Gynecology. 7th ed. New Delhi: Jaypee Brothers Medical Publishers (P) Ltd.; 2008: 599.

3. Mencaglia L, Scarselli G, Mencalagia L, Perinol, Hamousis. Hysteroscopy in perimenopausal and post-menopausal women with abnormal uterine bleeding. J Reprod Med. 1987;32(8):577-81.

4. Kurman RJ, Kaminski PF, Norris H. The behaviour of endometrial hyperplasia: a long term study of 'untreated' hyperplasia in 170 patients. Cancer. 1985;56(2):403-12.

5. John O. Schorge. Abnormal uterine bleeding. In: Joseph Schaffer, Lisa Halvorson, Barbara Hoffman, Karen Bradshaw John Schorge, eds. Williams
Gynaecology. 1st ed. New York: McGraw-Hill Companies; 2008: 367.

6. Ferri M. Ds and Cs: do;s and don'ts. Aust Fam Physician. 1983;12(11):783-5.

7. Yasmin F, Farrukh R, Kamal F. Efficacy of pipelle as a tool for endometrial biopsy. Biomedica. 2007;23:116-9.

8. Vaidya S, Lakhey M, Vaidya S, Sharma PK, Hirachand S, Lama S, et al. Histopathological pattern of abnormal uterine bleeding in endometrial biopsies. Nepal Med Coll J. 2013;15(1):74-7.

9. Bhavani N, Avanthi S, Aradhana G, Sangeeta C, Prasanna Kumar VS. A study of correlation between abnormal uterine bleeding and thyroid dysfunction. Int J Recent Trends Sci Tech. 2015;14(1):131-5.

10. Avantika G, Asmita MR, Usha M, Poonam R. Evaluation and histopathological correlation of abnormal uterine bleeding in perimenopausal women. Int J Biomed Advance Res. 2013;4(08):50913.

11. Gerald DF, Jonathan UA. Histopathological patterns of endometrial lesions in patients with abnormal uterine bleeding in a cosmopolitan population. J Basic Clin Reprod Sci. 2013;2(2):101-4.

12. Supriya S, Jayaprakash HT, Ashwini MC. Histopathological study of endometrium in abnormal uterine bleeding in different age groups. Int $\mathbf{J}$ Sci Res. 2014;3(11):422-4.

13. Nadia K, Farhan S, Sameera A. Comparison of efficacy and morbidity of pipelle vs. conventional endometrial sampling. Pak J Medl Heal Sci. 2012;6(2):1.

Cite this article as: Rachamallu L, Bhavani V, Byna P. Histological correlation of pipelle endometrial sampling with dilatation and curettage in abnormal uterine bleeding. Int J Reprod Contracept Obstet Gynecol 2015;4:1324-9. 